\title{
Heat-induced Denaturation of Myosin Total Rod
}

\author{
Kunihiko Samejima, Koui Takahashi* and Tsutomu Yasui* \\ Department of Dairy Science, The College of Dairying, \\ Ebetsu City, Hokkaido, Japan \\ * Department of Animal Science, Faculty of Agriculture, \\ Hokkaido University, Sapporo, Hokkaido, Japan
}

Received July 26, 1976

\begin{abstract}
The myosin total rod, which consists of smaller segments of light meromyosin and heavy meromyosin subfragment-2 (HMM S-2), prepared by limited papain digestion of rabbit myosin, was purified by Sepharose-2B column chromatography. The purified total rod was more homogeneous than any previously reported, and the sodium dodecyl sulfate (SDS) gel electrophoretic method yielded a molecular weight of $22-23 \times 10^{4}\left(11-11.5 \times 10^{4} \times 2\right)$.

Transition temperatures of this purified myosin total rod obtained from the melting profile during heating were 47.5 and $55^{\circ} \mathrm{C}$. The results of $\mathrm{ORD}$ and $\mathrm{CD}$ measurements showed almost full reversibility upon cooling after thermal treatment. However, the results obtained from difference spectra and fluorescence spectra showed incomplete reversibility with hysteresis.

This ostensible dichotomy concerning the structural thermostability of the rod portion of myosin molecule may mean that although ORD and CD studies show almost full reversibility of the helix-coil transition, local irreversible conformational changes, involving aromatic amino acid residues take place. This fact suggests that the renatured $\alpha$-rope of the myosin total rod can exhibit different properties than the native molecule under conditions where no discernible loss in helix content occurs.
\end{abstract}

It has been proposed, from molecular weight measurements on the isolated myosin rods and length determination on single molecules by electron microscopy, that the myosin rod consists of two $a$-helical polypeptide chains. It is also well known that the rod-like tail portion of myosin molecule in solution is virtually $100 \% \alpha$-helical.

Because knowledge of the heat-induced conformational transitions of the myosin rod is necessary to understand the thermal denaturation mechanism of myosin molecule, the stability of this $\alpha$-helical subfragment has been the subject of several recent papers. ${ }^{1 \sim 5)}$ Yasui et $a l^{6)}$ and Samejima et al. ${ }^{7)}$ have shown that light meromyosin fraction 1 (LMM purified by an ethanol precipitation procedure: LMM Fr 1) depolymerize to relatively low molecular weight proteins and peptides upon thermal treatment. Their results also have pointed out that the striking feature of the denaturation of this protein is rapid loss in paracrystal forming ability at low ionic strength.

Samejima et al., ${ }^{8)}$ on the other hand, have reported recently that both $\mathrm{LMM}-\mathrm{C}$ (myosin tail fragments obtained by treatment with cyanogen bromide) and LMM-BPNP ${ }^{9,10}$ (LMM fragments of myosin obtained by means of treatment with neutral protease from Bacillus polymixa) possess relatively high thermostability. From these results, they concluded that the rod portion of myosin molecules was substantially thermostable.

In our previous reports ${ }^{\hat{\alpha} 10)}$ denaturation studies were confined to the smaller segments (LMMs) and no information was gained regarding the total rod of myosin. It seems to be of importance to learn the behavior of the total rod portion of myosin under thermal treatment, for the rod portion of the protein must play some role in the development of the heat-gelling properties of meat in the presence of neutral salts. ${ }^{\text {I1 }}$ Hence, in the present study the structural stability of the column chromato- 
graphy-purified myosin rod (obtained by Sepharose-2B column chromatography: designated as CPR) has been examined, in order to obtain more insight into the nature of the conformational changes accompanying the thermal denaturation.

Our measurements of ORD and CD spectra indicate that the highly purified CPR exhibit changes in helical structure during thermal treatment which are almost completely reversible upon cooling. However, the results from difference spectra and fluorescence spectra show an incomplete reversibility with hysteresis, suggesting the existence of an irreversible local conformational changes in or on the molecule.

\section{MATERIALS AND METHODS}

Preparation of myosin. Myosin was prepared from fresh rabbit back and leg muscles by the method described by Perry. ${ }^{123}$

Preparation of total rod. Total rod was prepared from rabbit myosin according to Balint et al. ${ }^{13)}$ with slight modifications. Digestion was carried out for $10 \mathrm{~min}$ at $\mathrm{pH} 6.5$ in the presence of $20 \mathrm{mM} \mathrm{KCl}$, $20 \mathrm{~mm}$ phosphate buffer, $1 \mathrm{~mm}$ EDTA and $5 \mathrm{~mm} \beta$ mercaptoethanol, at $25^{\circ} \mathrm{C}$, with a soluble papain (Sigma Chemical Co.). Protein concentration of the reaction mixture was usually $10 \mathrm{mg} / \mathrm{ml}$.

Four $\mathrm{mg} / \mathrm{ml}$ of papain solution was activated by incubation for $1 \mathrm{hr}$ at $37^{\circ} \mathrm{C}$ in a solution containing $50 \mathrm{~mm}$ freshly dissolved cysteine, $10 \mathrm{~mm}$ EDTA and $33 \mathrm{~mm}$ phosphate buffer ( $\mathrm{pH}$ 7.0). After activation the papain was immediately used for digestion. A myosin to papain weight ratio of 150 was employed.

Digestion was terminated by the addition of freshly dissolved and neutralized iodoacetic acid in the final concentration of $2 \mathrm{~mm}$, and the digest was dialysed overnight against 20 vol. of $10 \mathrm{~mm}$ phosphate buffer (pH 7.0) with $1 \mathrm{~mm}$ iodoacetic acid. After centrifugation at $15,000 \mathrm{rpm}$ for $1 \mathrm{hr}$, the precipitate was dissolved at $0.5 \mathrm{M} \mathrm{KCl}$. To obtain the crude total rod fraction, alcohol treatment was used as described by Szent-Györgyi et al. ${ }^{2}$ )

Chromatographic procedure. Gel-filtration was carried out on Sepharose-2B manufactured by Phamacia, Sweden using a reversed-flow column $(2.7 \times$ $45 \mathrm{~cm}$ ). Samples of $50 \mathrm{mg}$ protein were consistently applied. The elutions were conducted upward at a constant rate of $20 \mathrm{ml} / \mathrm{hr}$ with a peristaltic pump. The temperature was maintained at $4^{\circ} \mathrm{C}$.
Viscosity measurements. Viscosity measurements were made with an Ostwald-type viscometer at $20^{\circ} \mathrm{C}$. Flow-time for solvent was 160 sec.

Polyacrylamide gel electrophoresis. All samples to be analysed were boiled for $3 \mathrm{~min}$ in the presence of $1 \% \operatorname{SDS}$ and $1 \% \beta$-mercaptoethanol to assure proper dissociation and to prevent degradation by proteolytic enzymes. $^{\text {i4) }}$ SDS-polyacrylamide gel electrophoresis was carried out according to Weber and Osborn $^{15)}$ with the use of gels containing $5 \%$ polyacrylamide. The length of gels was $10 \mathrm{~cm}$, and the current was $8 \mathrm{~mA}$ per tube.

Amino acid analysis. Amino acid analysis was carried out with a Hitachi Model 034 liquid chromatograph as previously described. ${ }^{\text {) }}$ The results are represented as an averaged value of duplicate analyses.

$O R D$ and $C D$ measurements. The measurements of ORD and CD were carried out with a JASCO ORD/UV-5 recording spectropolarimeter equipped with a $C D$ attachment as described previously.9) Calculations for helicity have been reported in detail elsewhere. ${ }^{8)}$

Difference spectrum. The ultraviolet difference spectrum was measured with a Hitachi recording spectrophotometer Type 323. The reference cell was maintained at a constant temperature $\left(20^{\circ} \mathrm{C}\right)$ and the sample cell was adjusted to varying temperatures $\left(20 \sim 70^{\circ} \mathrm{C}\right)$ by means of circulating water through separate jackets.

Fluorescence spectra. Fluorescence emission spectra were measured with a Hitachi MPF-2 spectrofluorimeter connected to a Hitachi recorder. The temperature of the cell compartment was controlled by circulating water.

Protein solutions containing $0.1 \mathrm{mg} / \mathrm{ml}$ of protein in $0.5 \mathrm{M} \mathrm{KCl}, 20 \mathrm{~mm}$ phosphate buffer $(\mathrm{pH} 7.0)$ and $1 \mathrm{~mm}$ EDTA were placed in a square quartz fluorescence cell $(3 \mathrm{ml})$ and equilibrated at the required temperature for $10 \mathrm{~min}$. The fluorescence intensity at $339 \mathrm{~nm}$ was continuously recorded. Exitation was at $290 \mathrm{~nm}$.

Electron microscopy. Electron microscopic observations were carried out with a Hitachi 11-B electron microscope as described in our previous paper.?

\section{RESULTS}

\section{Purification and some properties $C P R$}

Through out the purification procedure, with alcohol treatment and precipitation at low ionic strength after papain digestion, the 


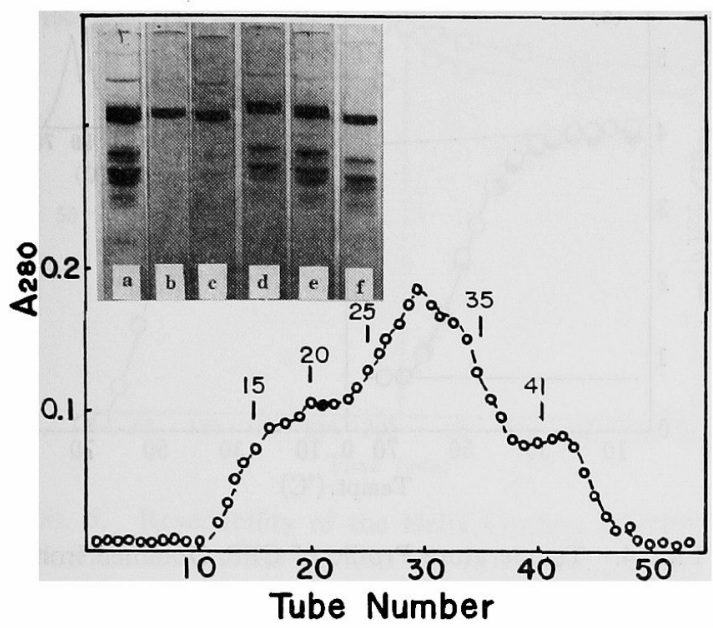

FIG. 1. Elution Profile of Myosin Total Rod by Gel Filtration on Sepharose-2B.

$50 \mathrm{mg}$ of protein was applied to a column equilibrated at $4^{\circ} \mathrm{C}$ with $0.5 \mathrm{M} \mathrm{KCl}$ and $10 \mathrm{~mm}$ phosphate buffer (pH 7.0). $6.0 \mathrm{ml}$ fractions were collected.

(Insert): SDS-gel electrophoresis of crude- and chromatographed myosin total rod preparations.

(a) illustrates the crude myosin total rod. (b) (f) indicate the fraction number of $15,20,25,35$ and 41 , respectively.

protein fraction was shown to be contaminated with smaller fragments as shown in Fig. 1 (a). For further purification the Sepharose-2B column was used employing $0.5 \mathrm{M} \mathrm{KCl}$ and $10 \mathrm{~mm}$ phosphate buffer (pH 7.0). Elution profiles of the myosin rod fraction on Sepharose-2B columns and the SDS-polyacrylamide gel electrophoretic patterns which correspond to the specified fraction numbers are illustrated in Fig. 1. The myosin rod from the front of the elution profile (Fraction numbers 15 20) was found to be far more homogeneous than the applied sample. Thus, the following experiments were performed using only the column purified rod (CPR).

Figure 2 shows the results of a typical experiment for molecular weight determination of CPR (Fraction number: 15 from Sepharose2B column chromatography) by SDS-polyacrylamide gel electrophoresis and its densitogram. From this result, the molecular weight was estimated to be $22-23 \times 10^{4}(11-11.5 \times$ $10^{4}$ for a single chain).

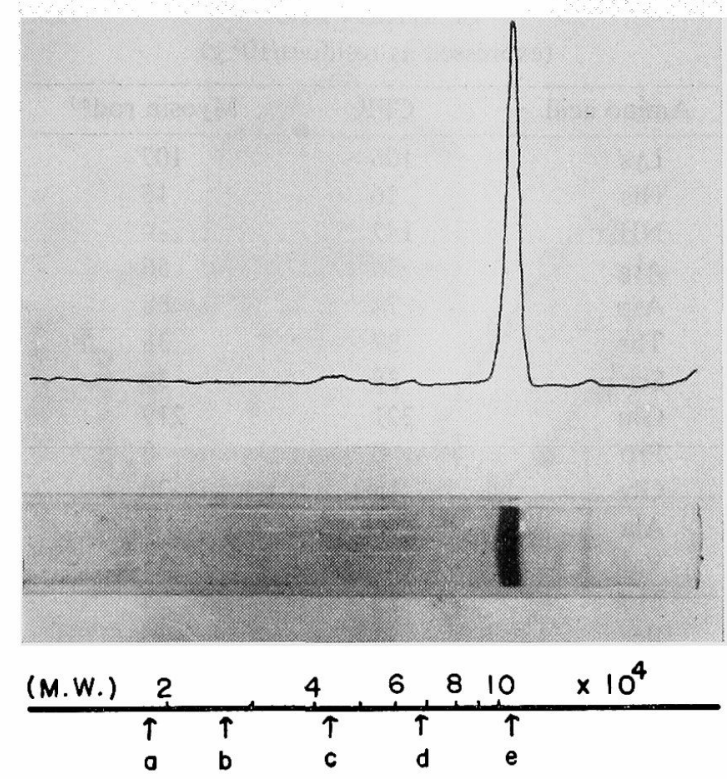

FIG. 2. SDS-polyacrylamide Gel Electrophoresis of CPR and Its Densitogram.

The four marker proteins used for molecular weight determination were myoglobin (a), chymotrypsinogen (b), ovalbumin (c) and bovine serum albumin (d). The extrapolated value (e) for CPR was approximately 115,000 .

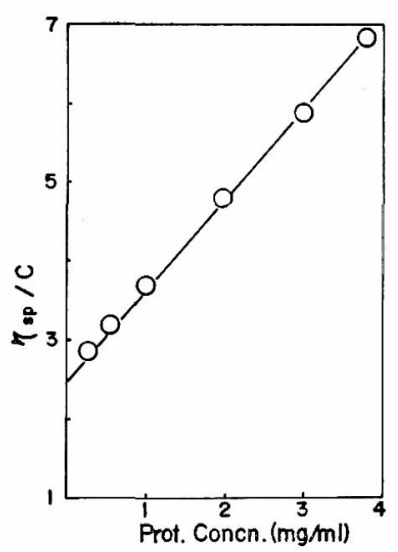

FIG. 3. Concentration Dependence of the Reduced Viscosity for CPR.

The measurements were carried out with $0.6 \mathrm{M} \mathrm{KCl}$, $20 \mathrm{~mm}$ phosphate buffer $(\mathrm{pH} 7.0)$ at $20^{\circ} \mathrm{C}$.

Figure 3 indicates the concentration dependence of the reduced viscosity for $\mathrm{CPR}$ in $0.6 \mathrm{M} \mathrm{KCl}$ and $20 \mathrm{~mm}$ phosphate buffer (pH7.0). The intrinsic viscosity of CPR $(2.4 \mathrm{dl} / \mathrm{g})$ gave a much higher value than any other LMMs 
Table I. Amino Acid Compositions OF MYOSIN ROD

(expressed as residues $/ 10^{5} \mathrm{~g}$ )

\begin{tabular}{lrc}
\hline Amino acid & CPR & Myosin rod $^{a)}$ \\
\hline Lys & 106 & 107 \\
His & 16 & 15 \\
$\mathrm{NH}_{3}$ & 147 & - \\
Arg & 56 & 56 \\
Asp & 74 & 88 \\
Thr & 37 & 38 \\
Ser & 38 & 39 \\
Glu & 221 & 219 \\
Pro & 0 & 0 \\
Gly & 15 & 20 \\
Ala & 79 & 85 \\
Val & 28 & 33 \\
Met & 28 & 23 \\
Ile & 38 & 36 \\
Leu & 102 & 99 \\
Tyr & 2 & 5.9 \\
Phe & 8 & 7 \\
\hline
\end{tabular}

a) Lowey et al. (1969).

obtained so far. ${ }^{9}$ The slope obtained from the plots of reduced viscosity $v s$. protein concentration of CPR also showed the steepest among all LMMs ever examined, suggesting the very high asymmetry of CPR.

The amino acid composition of CPR is shown in Table I. Like other $\mathrm{LMMs}^{9,26,17)}$ and HMM S-2 ${ }^{17}$ ) CPR contained no proline. However, it showed a high content of lysine, glutamic acid, aspartic acid, alanine and leucine. The amino acid profile of our purified rod segment is very similar to that of Lowey et al. ${ }^{27)}$

\section{Thermal denaturation of $C P R$}

A typical mean residue ellipticity $\left(-[\theta]_{222}\right)$ vs. temperature profile for CPR is presented in Fig. 4 (a). ORD and CD measurements were performed by a stepwise heating and cooling method using $1 \mathrm{mg} / \mathrm{ml}$ of protein in $0.5 \mathrm{M} \mathrm{KCl}$ and $20 \mathrm{~mm}$ phosphate buffer ( $\mathrm{pH} \mathrm{7.0)}$ solution. Almost complete reversibility of the value of $[\theta]_{222}$ was observed when the temperature of protein solution was lowered after stepwise heating to $70^{\circ} \mathrm{C}$, thus indicating that CPR was quite thermostable as is the case with LMM-C ${ }^{8}$ and LMM-BPNP.9) Figure 4 (a) also presents the extrapolations expected

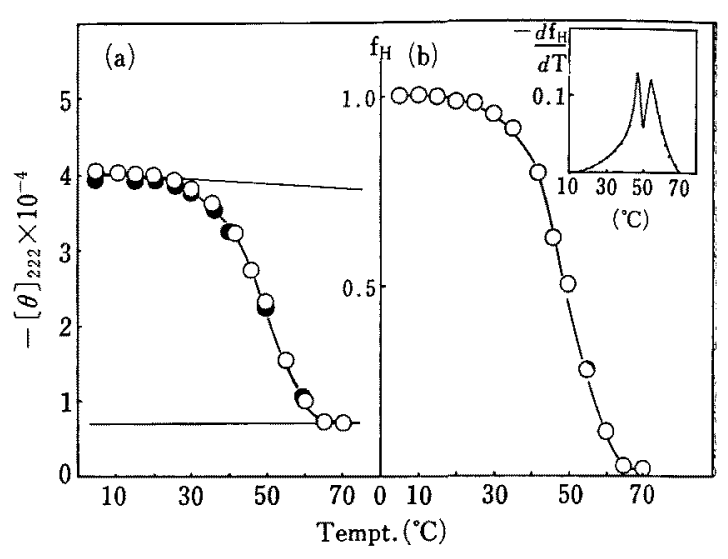

FIG. 4. Temperature Profile of CPR Obtained from CD Measurement.

(a) Changes in $[\theta]_{222}$ of CPR during thermal treatment.

The temperature of the protein solutions, which contained $1 \mathrm{mg} / \mathrm{ml}$ of CPR, $0.6 \mathrm{M} \mathrm{KCl}$ and $20 \mathrm{mM}$ phosphate buffer ( $\mathrm{pH} 7.0$ ), was raised $(0)$ or lowered (๑). Measurements were carried out with $1 \mathrm{~mm}$ quartz cell after 15 min-incubation at each temperature. The extraporated lines represent the thermal coefficients for the mean residue ellipticities of a double-stranded helix and random coil.

(b) Fraction of helix structure ( $\mathrm{fH}$ ) of $\mathrm{CPR}$ as a function of temperature.

(Insert): Derivative plot as a function of temperature.

from the thermal coefficients of $[\theta]_{222}$ for $100 \%$ double stranded $\alpha$-helix and $0 \%$ helix, and the data shall subsequently be presented as $\mathrm{fH}$ (fraction helix) vs. temperature profiles (Fig. 4 (b)) as described by Burke et al. ${ }^{18)}$ Derivative plots (Insert of Fig. 4) where $\mathrm{dfH} / \mathrm{dT}$ is plotted as a function of temperature have also been employed since this procedure yields accurate assignments of the transition temperature (Tm). The CPR yielded two transition points with $\mathrm{Tm}$ of 47.5 and $55^{\circ} \mathrm{C}$ from the data in Fig. 4(b).

Figures 5 (a) and (b) show the reversibility of helical content of CPR after thermal treatment at different time intervals. Similar results were obtained from both ORD (Fig. 5(a)) and CD (Fig. 5 (b)) measurements. Although reversibility of CPR decreased gradually as incubation time increased at $60^{\circ} \mathrm{C}$, there was almost full recovery of helical content when treated at $70^{\circ} \mathrm{C}$ for as long as $300 \mathrm{~min}$. At the moment, no satisfactory explanation for those phenomena can be offered. It must be 


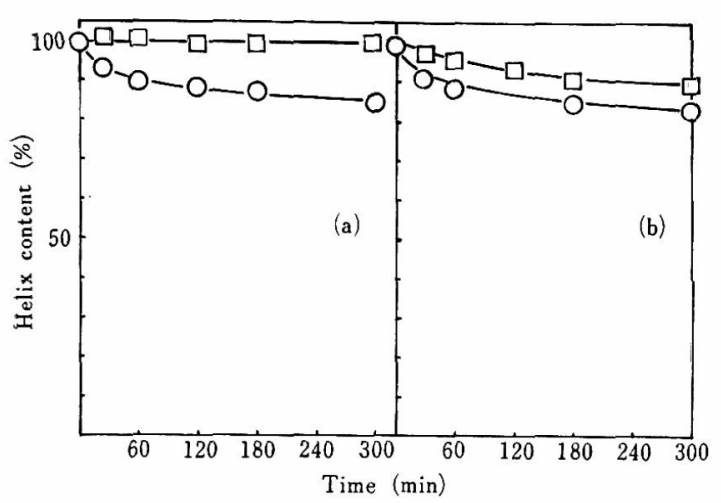

FIG. 5. Reversibility of the Helix Content of CPR Obtained from ORD (a) and CD (b) Measurements.

Protein $(1 \mathrm{mg} / \mathrm{ml})$ in $0.6 \mathrm{M} \mathrm{KCl}$ and $20 \mathrm{~mm}$ phosphate buffer ( $\mathrm{pH} 7.0$ ) were thermally treated for various periods of time at $60^{\circ} \mathrm{C}(O)$ or $70^{\circ} \mathrm{C}(\square)$. The measurements were carried out at $20^{\circ} \mathrm{C}$ after each thermal treatment.

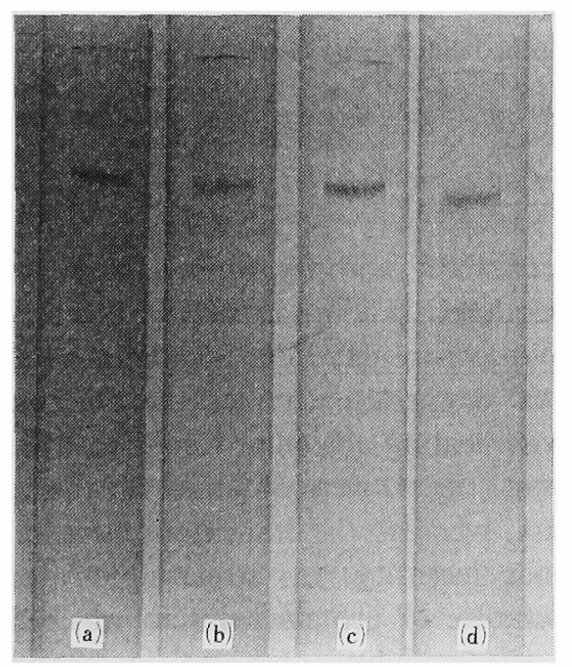

FIG. 6. Electrophoresis of CPR on SDS-polyacrylamide Gels.

Samples of $30 \mu \mathrm{g}$ were applied to the gels which were run at $8 \mathrm{~mA} /$ tube for $5 \mathrm{hr}$. (a) native, (b) $60^{\circ} \mathrm{C}$, $30 \mathrm{~min}$, (c) $60^{\circ} \mathrm{C} 60 \mathrm{~min}$, (d) $60^{\circ} \mathrm{C} 300 \mathrm{~min}$.

mentioned, however, that the apparent presence of two denatured products is a common feature of thermal denaturation of myosin rods irrespective of their preparative method; i.e., whether they are prepared by enzymatic digestion $^{7,19)}$ or by chemical cleavage ${ }^{7)}$ of peptide bonds.

As our protein sample was obtained by limited papain digestion of myosin, one must

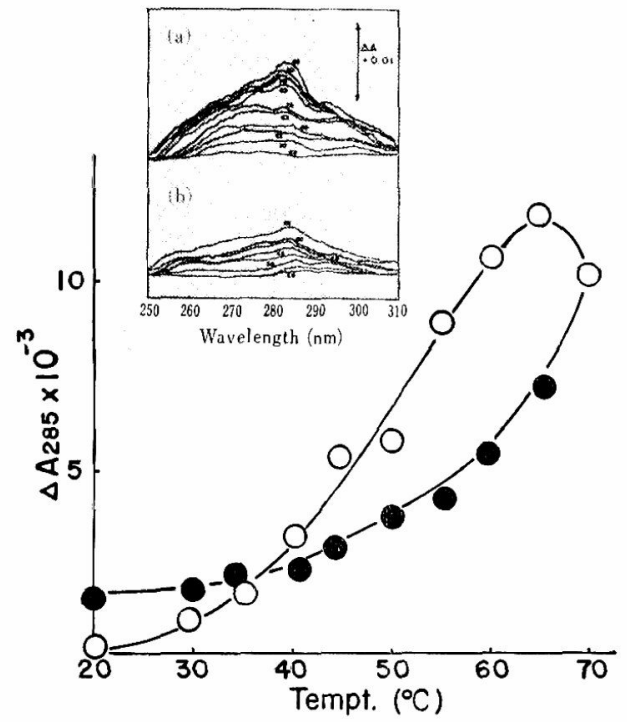

FIG. 7. Effects of Temperature on $-\Delta A_{285}$ of CPR.

$1.6 \mathrm{mg} / \mathrm{ml}$ of protein in $0.6 \mathrm{M} \mathrm{KCl}$ containing $20 \mathrm{mM}$ phosphate buffer ( $\mathrm{pH}$ 7.0) was incubated. Open symbols refer to changes in $-\Delta A_{285}$ when the temperature of solution was raised from $20^{\circ} \mathrm{C}$ to $70^{\circ} \mathrm{C}$, and solid symbols refer to that when the temperature of solution was lowered from $70^{\circ} \mathrm{C}$ to $20^{\circ} \mathrm{C}$.

(Insert); Differemce spectra of CPR induced by heating system (a) and cooling system (b).

consider the possibility that a portion of the proteolytic activity of papain survived and was adsorbed to the protein as in the case of tryptic LMM. ${ }^{7}$ To test the validity of this assumption CPR samples treated at various time intervals at $60^{\circ} \mathrm{C}$ were examined by SDS-polyacrylamide gel electrophoresis. The electrophoretograms shown in Fig. 6 clearly revealed that no fragmentation of CPR molecules into smaller polypeptides had occurred. Thus the changes in properties of the myosin rod as a result of thermal treatment may be a reflection of intramolecular conformational changes and not a proteolytic artifact.

As illustrated in Fig. 7, on the other hand, the $-\Delta A_{285}$ exhibited a slight change upon stepwise heating followed by gradual cooling, revealing an irreversible temperature profile with hysteresis as seen in the case of LMM Fr 1.7) However, the changes in helical content of CPR obtained from the result of CD measurement (Fig. 4) were found to be almost completely reversible. This result is rather 


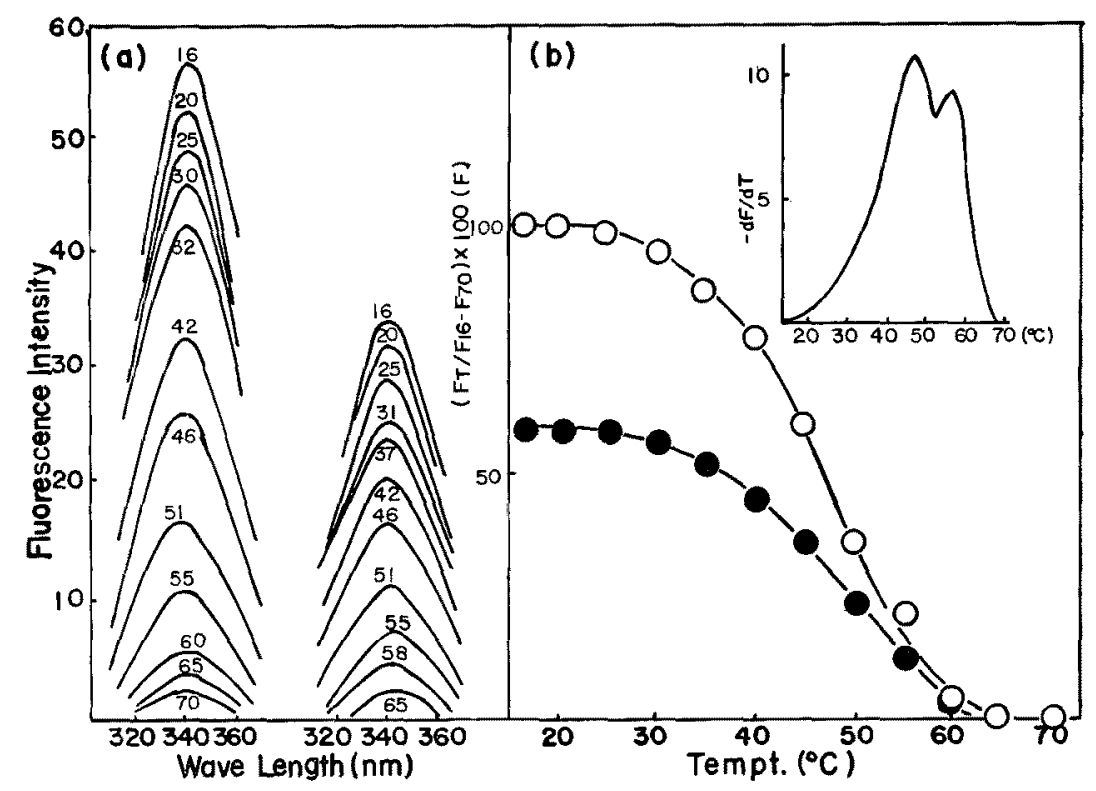

FIG. 8. Temperature Profile of CPR Obtained from Fluorescence Spectra.

(a) Fluorescence spectra of CPR induced by heating (left) and cooling (right) systems.

The spectra were recorded at the indicated temperature $\left({ }^{\circ} \mathrm{C}\right)$.

(b) Changes in relative fluorescence intensity of CPR at $339 \mathrm{~nm}$. Symbols were the same as described in Fig. 7.

(Insert): Derivative plot as a function of temperature.

surprising, when we recall the previous evidence reported on LMM Fr $1,{ }^{7}$ in which the temperature profile of $-\Delta A_{2 \varepsilon 5}$ was consistent with that of the $b_{0}$ value accompanied by the fragmentation of the molecules. Since changes in $-\Delta A_{285}$ result from local conformational changes in polypeptide chain residing aromatic amino acid residues (mainly tryptophan residues), emission fluorescence measurements were used to follow the unfolding of the myosin rod, because Gally and Edelman ${ }^{20}$ have indicated that the shapes of the emission spectra for the different proteins (pepsin, ovalbumin, lysozyme and human $\gamma$-globulin) remain unaltered, though the quantum yield of emission decreases as the temperature increases.

Figure 8 (a) shows the fluorescence spectra of CPR obtained by stepwise heating and cooling. The results indicate that the fluorescence intensity of CPR gradually increases or decreases concurrently with the rise or fall of temperature of the protein solution. The transition curve in Fig. 8 (b) was obtained from the difference of fluorescence intensity between CPR and tryptophan itself at each temperature. The insert of Fig. 8 is a derivative plot, where $\mathrm{dF} / \mathrm{dT}$ is calculated as a function of temperature under the condition of stepwise heating. Similar results to $C D$ measurement (Fig. 4) were obtained for the heating process, whereas the transition curve of fluorescence intensity was irreversible when the temperature of protein solution was reduced. This irreversibility observed in changes in fluorescence spectra of CPR was consistent with the results of difference spectra measurements (Fig. 7). The values of $\mathrm{Tm}$ obtained from the heating system, however, were 47.5 and $55^{\circ} \mathrm{C}$, which were exactly the same as those obtained from $\mathrm{CD}$ measurement (Fig. 4). Therefore, it may be said that the fluorescence measurement is a sensitive and reliable method for denaturation studies of the protein.

To prove that the irreversibility of transition curves shown in Fig. 8 (b) is not the result of disruption of internal peptide linkages during proteolysis, the chemically cleaved tail portion, LMM-C, was used for the same experiment. 


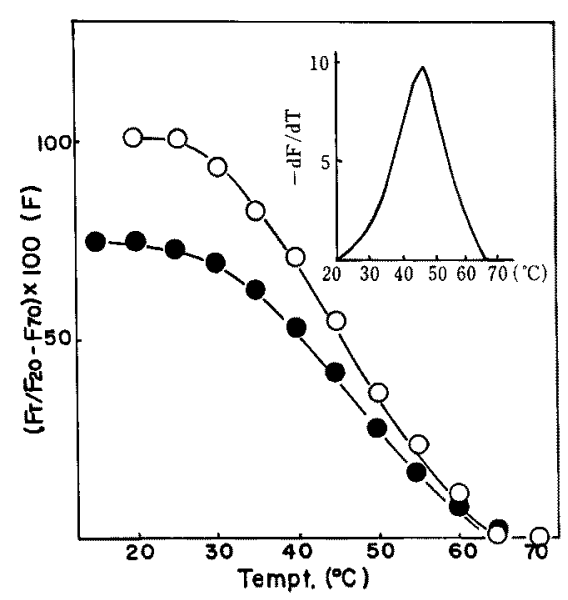

FIG. 9. Changes in Relative Fluorescence Intensity of $\mathrm{LMM}-\mathrm{C}$.

Conditions and symbols were the same as described in Fig. 8.

(Insert): Derivative plot as a function of temperature.

The transition curve obtained from fluorescence measurements for $\mathrm{LMM}-\mathrm{C}$ is shown in Fig. 9. LMM-C yielded a single transition with $\mathrm{Tm}$ of $46^{\circ} \mathrm{C}$, which was in good agreement with those of LMM-BPNP( ${ }^{9}$ and LMM Fr 1. ${ }^{18)}$ The temperature profiles of LMM-C also showed irreversibility when the temperature of the solution was reduced.

Figure 10 (a) shows the paracrystal of CPR formed at $\tau / 2=0.1$ from the native protein by dilution. When $\mathrm{CPR}$ in $0.6 \mathrm{M} \mathrm{KCl}$ solution was incubated at $60^{\circ} \mathrm{C}$ for $30 \mathrm{~min}$, and brought to the same ionic environment as the control by dilution, the number of the paracrystals observed in electron microscopic field was decreased, and it should be emphasized that the paracrystals formed after the thermal treatment were looser than the controls (Fig. 10 (b)). However, paracrystal forming ability still remained even after treatment for $30 \mathrm{~min}$ at $60^{\circ} \mathrm{C}$. In Fig. $10(\mathrm{c})$, the paracrystals of CPR, formed at $\tau / 2=0.2$ from the native protein, are shown. The apparent morphorogical similarity beiween native CPR at $\tau / 2=$ 0.2 , with heat-treated one at $\tau / 2=0.1$, leads us to the conclusion that a subtle conformational change of the molecule might give rise to the weakening of the intermolecular attractive forces which are specific for the native molecules. $^{211}$

\section{DISCUSSION}

Burke et al. ${ }^{18}$ indicated that the protein in their myosin rod preparation had molecular weights of $100,000 \pm 10,000, \quad 70,000 \pm 5,000$ and $24,000 \pm 6,000$, from SDS-polyacrylamide gel electrophoresis patterns. They believed that the two lower molecular weight bands arise from SDS denaturation of a small proportion of rod molecules which contain a few internal peptide cleavages, since high-speed sedimentation equilibrium experiment on the rod showed no evidence of heterogeneity. ${ }^{22 r}$ However, we have found it possible to prepare a highly purified myosin total rod by means of a Sepharose-2B column (Figs. 1 and 2). These results, therefore, enable us to suggest that the two lower molecular weight materials of Burke et $a{ }^{18)}$ might be fragments produced by papain digestion.

As shown in the present paper, from the results of $C D$ measurement (Fig. 4), the temperature profile of CPR was almost completely reversible. If, on the other hand, similar experiments were undertaken using the later fractions (numbers from 35 to 41 ) of Sepharose-2B column elution (Fig. 1) as a sample, the helical content of these lower molecular weight subfragments was gradually and irreversibly decreased during the course of thermal treatment (unpublished data). This phenomenon was similar to the depolymerization behavior of LMM Fr 1 solutions upon heating. ${ }^{4,6,7)}$ However, as indicated earlier in Fig. 6, thermal disintegration of polypeptide linkage would not be expected to occur in this case. Fragmentation of the myosin rod by proteolysis into molecules smaller than some critical length probably nullifies part of the apparent reversibility of the helix-coil transition due to thermal treatment, and it is therefore important to prepare the more highly purified myosin rod (Fig. 2) to use in experiments involving the denaturation of the myosin rod. 
Our myosin rod preparation yielded two Tm values of 47.5 and $55^{\circ} \mathrm{C}$ (Figs. 4 and 8), while Burke et $a l{ }^{18)}$ reported that their rod prepa- ration yielded two $\mathrm{Tm}$ values of 44 and $55^{\circ} \mathrm{C}$ under similar conditions. Goodno and Swenson $^{23)}$ also reported their myosin rod
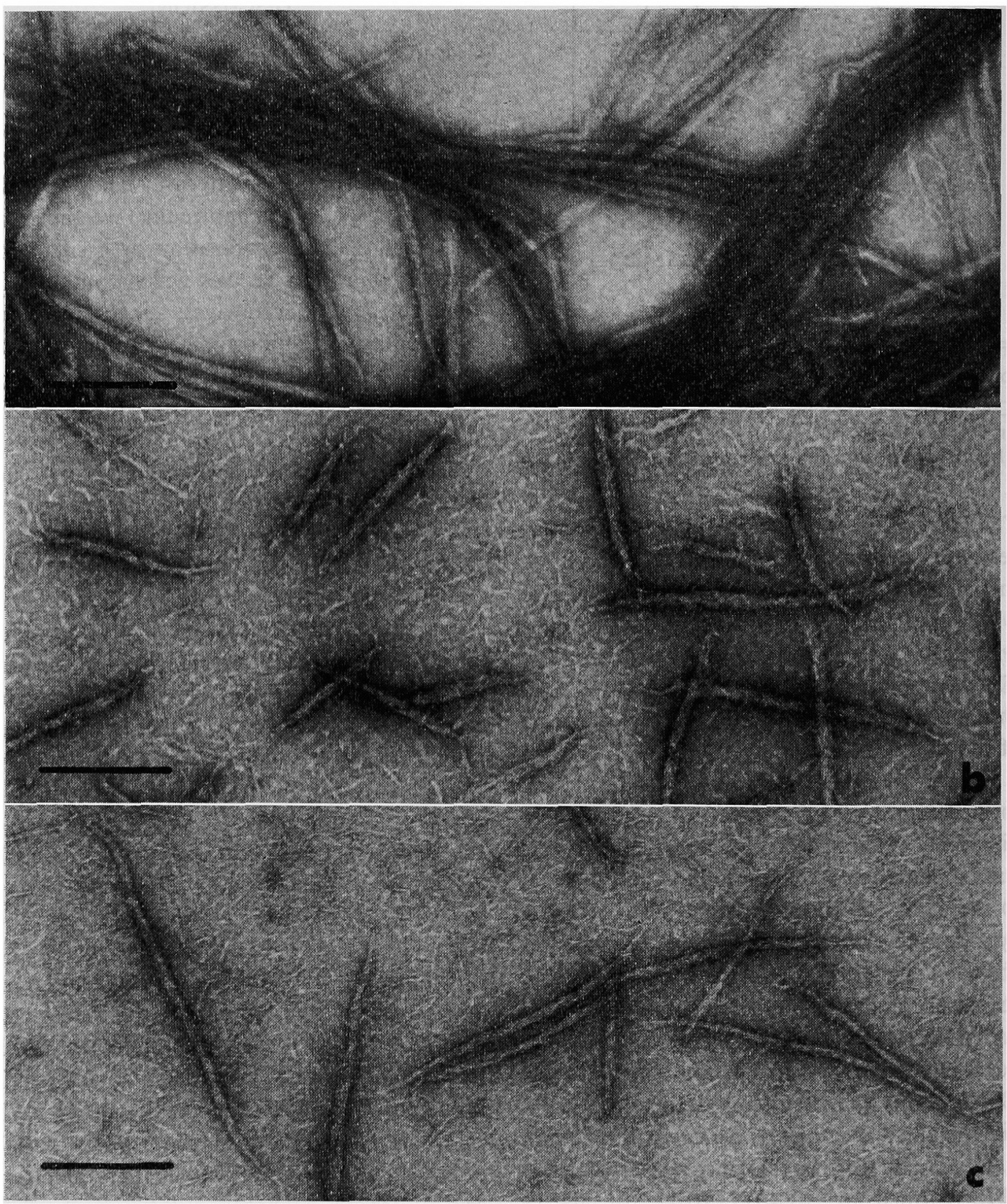

FIG. 10. Effect of Thermal Treatment on the Paracrystal Formability of CPR. Bar length: $0.2 \mu$

(a) Electron micrograph of CPR paracrystal formed when ionic strength was reduced to 0.1 by dilution.

(b) Electron micrograph of thermally treated CPR.

Protein in $0.6 \mathrm{M} \mathrm{KCl}$ and $10 \mathrm{~mm}$ phosphate buffer (pH 7.0) was thermally treated at $60^{\circ} \mathrm{C}$ for $30 \mathrm{~min}$, cooled and then ionic strength of the solution was reduced to 0.1 .

(c) Electron micrograph of CPR paracrystal formed when ionic strength was reduced to 0.2 by dilution. 
exhibited a $\mathrm{Tm}$ value of about $43^{\circ} \mathrm{C}$. It seems, therefore, probable that the difference between our and their results in the lower Tm value may originate from lower molecular weight subfragment contamination (or the difference in preparation). The $\mathrm{Tm}$ values of myosin, ${ }^{23,24)}$ actomyosin $^{24)}$ and myosin tail portion ${ }^{9,22,23}$ obtained from measurements of changes in viscosity, ORD, $\mathrm{pH}$ and emission fluorescence (Fig. 8) were fairly similar to one another. Those results support the conclusion of Goodno and Swenson that the globular portion of myosin molecule (HMM or HMM subfragment 1) either has a Tm almost identical with that of the myosin tail portion or make no contribution to the melting curve. Consequently, it may be reasonable to assume that the myosin tail portion exerts an important influence on alterations in the structure of the molecules during thermal denaturation of myosin.

The native myosin rod in $0.6 \mathrm{M} \mathrm{KCl}$ solution showed a helicity of $100 \%\left(\left[\mathrm{~m}^{\prime}\right]_{233}=-12,700\right)$. When the protein solution was dissolved in $5 \mathrm{M}$ guanidine- $\mathrm{HCl}(\mathrm{Gu}-\mathrm{HCl})$ after thermal treatment $\left(60^{\circ} \mathrm{C}\right.$ for $\left.30 \mathrm{~min}\right)$, its helix content decreased to $18 \%\left(\left[m^{\prime}\right]_{233}=-2,281\right)$, indicating almost complete unfolding. If, however, Gu$\mathrm{HCl}$ was removed from the protein solution by dialysis against excess $0.6 \mathrm{M} \mathrm{KCl}$, the helical structure of the protein solution showed a full recovery $\left(\left[m^{\prime}\right]_{233}=-13,006\right)$. These results indicated that all the non-covalent linkages in the heat-denatured myosin rod were ruptured, forming a random-coil configuration in the presence of $5 \mathrm{M} \mathrm{Gu}-\mathrm{HCl}$. These results clearly indicate that gross alteration of the structure of the myosin tail portion, induced by thermal and $\mathrm{Gu}-\mathrm{HCl}$ treatments, is brought about by disruption of stabilizing forces of a noncovalent nature, like hydrogen bonds, electrostatic and hydrophobic interactions and that disulfide links or other covalent bonds are not involved.

Though the changes in $-\Delta A_{285}$ of CPR were remarkably smaller than that of LMM Fr $1^{7)}$ during stepwise heating and cooling, an apparent irreversibility was observed after cooling
(Fig. 7). Emission fluorescence measurements on CPR (Fig. 8) showed similar results. These results are not consistant with those obtained from ORD and CD measurements (Figs. 4 and 5). In spite of the ostensible reversibility of gross structure in the whole molecule during thermal treatment, these facts imply that during thermal treatment aromatic amino acid residues (especially tryptophan residues) are gradually transferred from a moderately hydrophobic environment inside the protein molecule to an exposed polar environment and never return to their original position upon cooling. The evidence presented in Fig. 9 gives full support for the validity of the proposal described above.

It is, therefore, conceivable that at least in the case of myosin total rod, thermostability has to be ascribed not to the whole molecule but rather to the rod portions of the molecule. Thus the irreversibility of temperature profiles shown by measurements of difference spectrum and emission fluorescence indicates that the course of unfolding is well in accord with those of ORD and CD measurements, whereas conformation of the refolded state is locally different from the native $\alpha$-helical rope, though ORD and CD data apparently demonstrate complete restoration of helicity. The hysteresis observed in Fig. 7 provides an additional evidence that the refolding process is not merely a reversal of the unfolding process.

We believe that these subtle changes in local conformation of the renatured (refolded) myosin rod can have potentially significant effects on the gelation or coagulation of myosin, which usually accompanies denaturation of the molecule by heating.

Acknowledgement. The authors wish to express their gratitude to Dr. F. H. Wolfe of the Department of Food Science, The university of Alberta, Edmonton, Canada for reading this manuscript. This investigation was supported in part by the grants from the Ministry of Education of Japan and the Kuribayashi Foundation.

\section{REFERENCES}

1) A. G. Szent-Györgyi and M. Borbiro, Arch. 
Biochem. Biophys., 60, 180 (1956).

2) A. G. Szent-Györgyi, C. Cohen and D. E. Philpott, J. Mol. Biol., 2, 133 (1960).

3) M. Balint, L. Szilagyi, G. Fekete, M. Blazso and N. A. Biro, ibid., 37, 317 (1968).

4) E. F. Woods, Intern. J. Protein Res, 1, 29 (1969).

5) M. Balint, A. Schaefer and N. A. Biro, Acta Biochim. et Biophys, Acd. Sci. Hung., 5, 45 (1970).

6) T. Yasui, Y. Yazawa, K. Takahashi and K. Samejima, Agr. Biol. Chem., 35, 1236 (1971).

7) K. Samejima, J. Morita, K. Takahashi and T. Yasui, J. Biochem., 71, 661 (1972).

8) K. Samejima, K. Takahashi and T. Yasui, Agr. Biol. Chem., 37, 477 (1973).

9) K. Samejima, K. Takahashi and T. Yasui, ibid., 38, 1049 (1974).

10) K. Samejima and T. Yasui, Jap. J. Zootech. Sci., 47, 147 (1976).

11) K. Samejima, Y. Hashimoto, T. Yasui and T. Fukazawa, J. Food Sci., 34, 242 (1969).

12) S. V. Perry, "Methods in Enzymology," Vol. II, ed. by S. P. Colowick and N. O. Kaplan, Academic Press Inc., New York, N. Y., 1955, pp. 582 588.

13) M. Balint, L. Menczel, E. Fejes and L. Szilagyi,
Acta Biochim. et Biophys. Acad. Sci. Hung., 7, 215 (1972).

14) J. R. Pringle, Biachem. Biophys. Res. Commun., 39, 46 (1970).

15) K. Weber and M. Osborn, J. Biol. Chem., 244, 4406 (1969).

16) M. Young, M. H. Blanchard and D. Brown, Proc. Natl. Acad. Sci. U. S., 61, 1087 (1968).

17) S. Lowey, H. S. Slater, A. G. Weeds and H. Baker, J. Mol. Biol., 42, 1 (1969).

18) M. Burke, S. Himmelfarb and W. F. Harrington, Biochemistry, 12, 701 (1973).

19) K. Samejima and T. Yasui, J. Food Sci., 40, 451 (1975).

20) J. A. Gally and G. M. Edelman, Biochim. Biophys. Acta, 60, 499 (1962).

21) R. F. Siemankowski and C. R. Zobel, ibid., 420, 406 (1976).

22) W. F. Harrington and M. Burke, Biochemistry, 11, 1448 (1972).

23) C. C. Goodno and C. A. Swenson, ibid., 14, 867 (1975).

24) A. L. Jacobson and J. Henderson, Can. J. Biochem., 51, 71 (1973). 